Research Article

\title{
Research on the Impact of Different Force Directions on the Mechanical Properties and Damage Evolution Law of Sandstone with Different Hole Diameters
}

\author{
Fukun Xiao $(\mathbb{D}$, Renhe Li $(\mathbb{D}$, and Le Xing $\mathbb{D}$ \\ Heilongjiang Ground Pressure \& Gas Control in Deep Mining Key Lab, Heilongjiang University of Science \& Technology, \\ Harbin 150022, China \\ Correspondence should be addressed to Fukun Xiao; xiaofukun@hotmail.com
}

Received 3 July 2021; Revised 3 August 2021; Accepted 16 August 2021; Published 26 August 2021

Academic Editor: Guang-Liang Feng

Copyright (c) 2021 Fukun Xiao et al. This is an open access article distributed under the Creative Commons Attribution License, which permits unrestricted use, distribution, and reproduction in any medium, provided the original work is properly cited.

In this research, a uniaxial acoustic emission experiment was conducted on rock samples with different positions and diameters of the hole, and an analysis was made on the impact of different hole positions and diameters on the mechanical properties, failure, energy conversion, and acoustic emission-caused damage characteristics and laws of the rock samples. The results reveal as follows: first, due to the existence of holes in rocks, the stress-strain curve changes at each stage, accompanied by multiple stress drops. And the peak strength gradually reduces with the increase in hole diameter. At different hole positions, the duration that the rock sample passes through at each stage of the stress-strain curve varies, and the peak strength of the rock with the vertical hole is greater than that of the rock with the horizontal hole. This indicates that the bearing capacity and stability of the rock sample with the vertical hole are greater than those of the rock sample with the horizontal hole of the same diameter. Second, by making a comparison on the failure characteristics of rock samples, it is found that the intact rock shows brittle failure. For the rock sample with the horizontal hole, symmetrical tensile cracks initially appear in the upper and lower parts of the hole and finally form shear failure. As for the rock sample with the vertical hole, Y-shape failure originally presents and eventually forms $\mathrm{N}$-shape failure with the increase in hole diameter. Over a comparison with the failure pattern of an intact rock sample, it is demonstrated that the final failure pattern and crack expansion trend on the rock sample vary with the change in the hole position and diameter. Third, as obtained by comparing and analyzing the energy conversion of the rock with different diameters of the hole, the energy conversion in the rock is changed due to the existence of holes, and the increase in hole diameter causes a gradual decrease in the elastic energy stored in the rock and gradual increase in the dissipated energy. And by comparing the energy conversion of the rock with different positions of the hole, it is acquired that the elastic energy conversion ratio of the rock with the vertical hole is higher than that of the rock with the horizontal hole. Furthermore, an explanation was made on the difference in the failure processes of the two types of rocks from the perspective of energy conversion.

\section{Introduction}

There are many causes for the rock failure, and one of the important causes is the existence of natural hole in the rock, mainly for the reason that the size and distribution of the hole in the rock are inseparable from the mechanical properties of the rock [1]. A large number of research studies have demonstrated that rock failure is a process of generation, evolution, and penetration of cracks, and defective hole in the rock is a key factor that leads to rock failure [2].
For this reason, researchers both in China and foreign countries have conducted a large number of theoretical and experimental research studies on the prefabricated rock with holes. First of all, in terms of theories and experiments, Lajtai $[3,4]$ artificially simulated rocks with the hole by using gypsum and studied the evolution process of cracks around the hole by uniaxial compression. The research results reveal that some primary pulling cracks, positive shear cracks, secondary pulling cracks, and oblique shear cracks appear during the failure process of the rock; Yang et al. [5-7] 
conducted uniaxial compression test on sandstone and marble with a single hole. Consequently, crack appeared around the hole, which was caused by the concentration of tensile stress. Later, the crack gradually expanded toward the edge or weak part of the rock along the loading direction which revealed that the heterogeneity of the rock had a huge impact on the expansion of the crack on the rock. Li et al. $[8,9]$ conducted uniaxial compression and blow tests on slab-like granite and marble with the hole and analyzed the vital role that the splitting tensile damage occurred around the hole played in rock failure, where the elastic-plastic rockburst characteristics of the rock also evolved around the hole. Tang and $\mathrm{Xu}$ and Liu et al. $[10,11]$ established an acoustic emission damage model and conducted uniaxial compression on it, obtaining the equation curve of the damage evolution rule. Li et al. [12-14] found that mechanical parameters and acoustic emission characteristics were affected by the distribution of cracks on the rock containing hole. The research result demonstrates that emission is one of the key means of studying the damage evolution of the rock, and in this evolution process, the rock shows significant crack expansion and acoustic emission characteristics. In the research of Yankui and Nie [15], compression test was conducted on a rock with the hole and crack. Their research results demonstrate that the crack has a greater impact on the mechanical properties of the rock than the hole, different from the acoustic emission characteristics of the rock without the hole and crack.

Feng et al. $[16,17]$ obtained the discrimination method of tunnel rockburst by abstracting the rock with holes; it is the existence of the hole and crack that change the acoustic emission characteristics of the rock with the hole and crack. As known by analyzing the research studies on the damage failure of the defective coal rock, the current research studies on the impact of the hole on rock failure only focus on analysis from the macrofailure perspective of the rock, and few research studies involve the distribution of stress in the pressurized rock with the hole and the impact of stress distribution on the crack failure of the rock with the hole in the loading process. In addition to the failure caused by the internal defect of the rock, the position of the hole should also be taken into consideration because the direction of the stress acting on the hole at different positions varies, and the impact on the rock failure is also quite different. However, there are few achievements in studying the impact of the hole position on rock failure.

In view of this, from the macroperspective and energy dissipation perspective, this paper analyzes the damage and change of macromechanical behavior of the porous rock by monitoring acoustic emission and simulating the stress distribution of the porous rock during loading. The conclusion obtained is of certain significance for guiding the stability control of the defective surrounding rock, the driving in the well, and the selection of the supporting measure in the face of the surrounding rock with the hole.

\section{Materials and Methods}

2.1. Materials. The rock samples were black stones collected from a mining area. Considering the influence on mechanical properties of the rock sample with the hole, the processed rocks were bored in two steps. First, high-precision electric drill was used to bore on the rock for the first time due to the difficulty in initial boring. Second, after initial boring, existing hand drill was used to conduct secondary fining-off and finally produce rock samples with the vertical hole and horizontal hole of different diameters (respectively, $5 \mathrm{~mm}, 10 \mathrm{~mm}$, and $15 \mathrm{~mm}$ ).

According to regulations relevant to the mechanical test on rocks and considering the test error caused by experimental loading equipment, data acquisition, and a series of manual misoperations, the quantity of rock samples prepared for the experiment was not less than 4 and that actually used in the experiment was not less than 3 . The experimental result is the average value of the results obtained. The prepared rock samples are as shown in Figure 1 and numbered as shown in Table 1 .

2.2. Experimental Loading Procedures. A digital camera was aligned with the rock sample. Four acoustic emission probes were arranged around the rock sample with the hole to count and acquire the energy emitted by acoustic emission. Then, the evolution rule of the entire rock failure was observed via the camera in combination with the acoustic emission system and electrohydraulic servo press (see Figure 2).

The uniaxial compression device was loaded by displacement at a speed of $0.01 \mathrm{~mm} / \mathrm{sec}$.

The camera adopted an acquisition speed of $0.5 \mathrm{~s} /$ picture. Moreover, in the experiment, the uniaxial compression device and acoustic emission device were started at the same time in order to ensure the preciseness of the experiment and the consistency in the experimental data. The impact of the external environment on the correctness of the experimental result and personnel walking around were reduced as much as possible, and the door and windows were closed during the experiment.

\section{Analysis of Mechanical Properties and Failure Law}

3.1. The Impact of Different Hole Diameters on the Mechanical Characteristics of the Rock Sample. As can be seen from Figure 3, stress-strain curves of the intact rock sample show significant brittle failure. Due to the existence of the hole, stress-strain curves of the rock sample in the elastic stage are short compared with those of an intact rock sample, and those in the yield stage are prolonged relatively.

However, the stress concentration around the hole becomes very strong, and this part of the rock is easier to enter the destructive stage. With the increase of hole diameter, the failure will become more obvious.

As presented in Figure 3(a) for the horizontal hole, the stress change of the rock in the compression stage is obvious and in an arc shape. Before reaching the peak point, the stress falls apparently, where sample B05 with $\Phi 5 \mathrm{~mm}$ hole shows two stress drops: the stress is dropped by $3.4 \mathrm{MPa}$ for the first time when reaching 39.6 MPa and by 2.6 MPa for the second time when reaching $42 \mathrm{MPa}$. Sample C10 with 


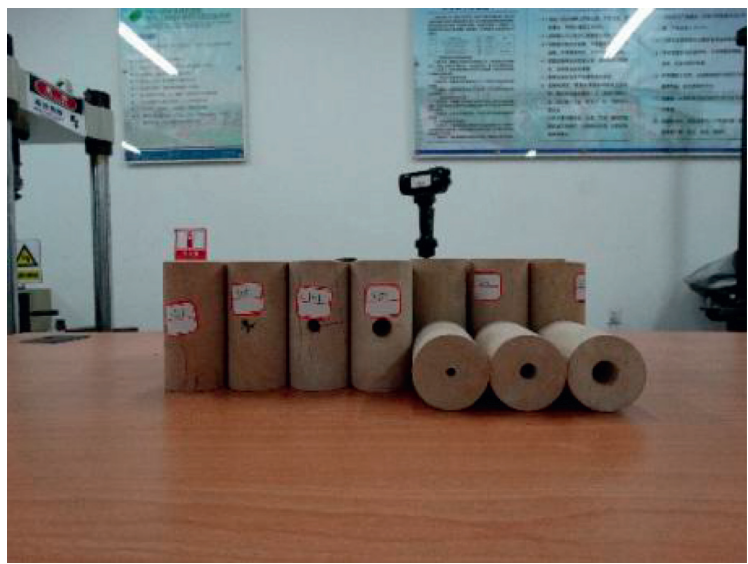

FIGURE 1: Samples with different hole positions and diameters.

TABLE 1: Sizes and mass of rock samples with different hole positions and diameters.

\begin{tabular}{lccc}
\hline Sample no. & Hole diameter, in $\mathrm{mm}$ & Hole position & Average mass, in $g$ \\
\hline A00 (1234) & 00 & N/A & 99 \\
B05 (1234) & 05 & Horizontal & 95 \\
C10 (1234) & 10 & Horizontal & 88 \\
D15 (1234) & 15 & Horizontal & 80 \\
E05 (1234) & 05 & Vertical & 93 \\
F10 (1234) & 10 & Vertical & 88 \\
G15 (1234) & 15 & Vertical & 81 \\
\hline
\end{tabular}

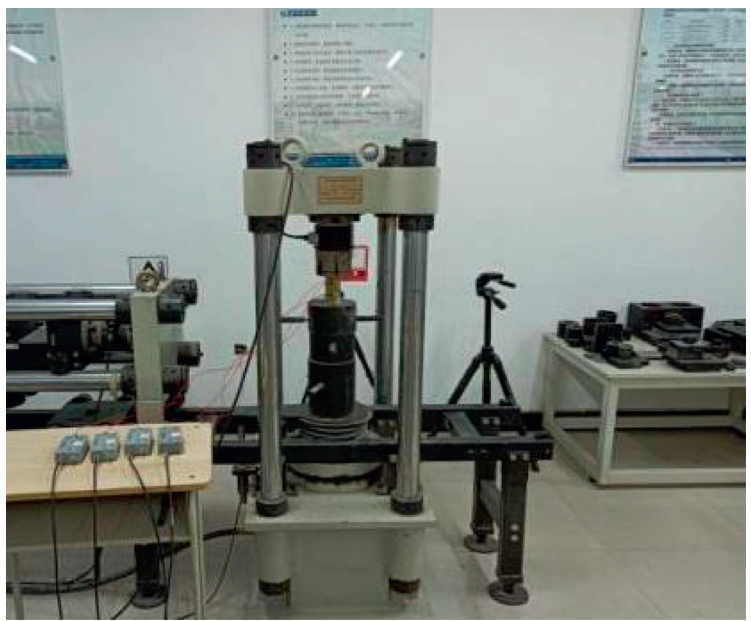

FIGURE 2: Site of the acoustic emission monitoring experiment under uniaxial compression.

$\Phi 10 \mathrm{~mm}$ hole also undergoes two stress drops: the first drop is $3.4 \mathrm{MPa}$ when the stress reaches $26.5 \mathrm{MPa}$, and the second drop is $3.1 \mathrm{MPa}$ but occurs after the stress reaches the peak point. Sample D15 with $\Phi 15 \mathrm{~mm}$ hole only has one stress drop, and the drop is merely $0.75 \mathrm{MPa}$, while as shown in Figure 3(b) for the vertical hole, only sample C10 with $\Phi 10 \mathrm{~mm}$ hole shows one stress drop, which indicates that the rock with the vertical hole has good stability. Compared with the brittle failure characteristics of the intact sample, after the stress on this sample reaches the peak point with the increase in hole diameter, almost all the samples with holes obtain certain bearing capacity and undergo a repetitive process (drop and then rise) in stress after reaching the peak point. This is mainly because of the buckling failure that occurred on the rock sample due to unceasing expansion and penetration of the interior cracks. In the failure stage, the rock sample with the hole shows obvious stress drops. As observed via the high-speed camera, every stress drop is accompanied by the generation, expansion, and penetration of new cracks.

According to Figure 4, the hole diameter has a great impact on peak strength of the rock sample with the hole and is inversely proportional to the peak strength. As for the peak stress on the rock with different diameters of the horizontal hole (Figure 4(a)), the average peak stress on the intact rock in the failure state is $75.1 \mathrm{MPa}$. If the hole diameter is $5 \mathrm{~mm}$, 


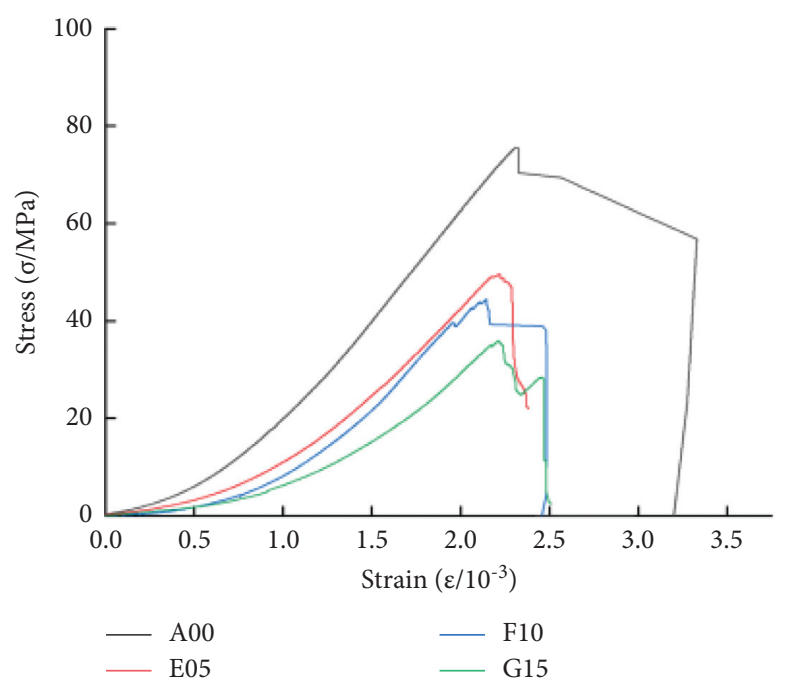

(a)

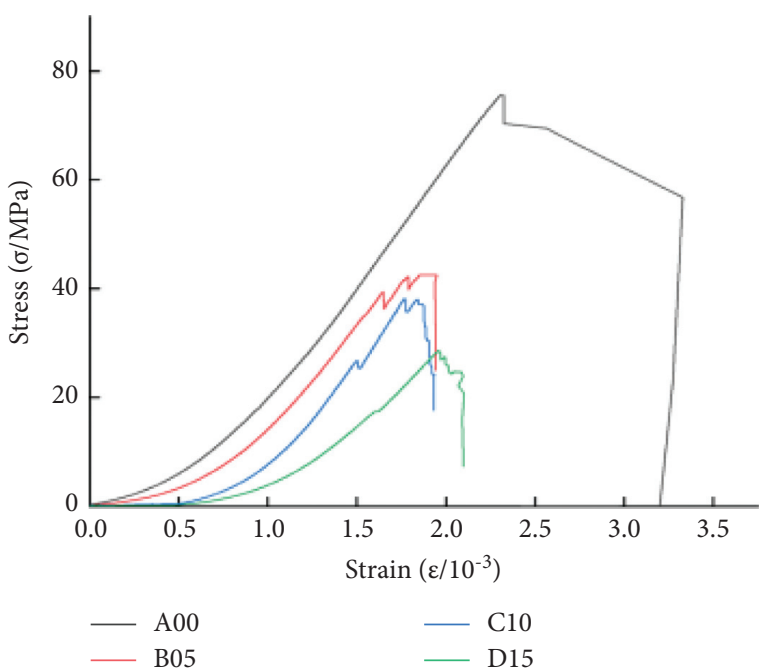

(b)

FiguRE 3: Stress-strain curves of the rock with different diameters of the hole. (a) Stress-strain curves of the rock with different diameters. (b) Stress-strain curves of the rock with different hole orientations.

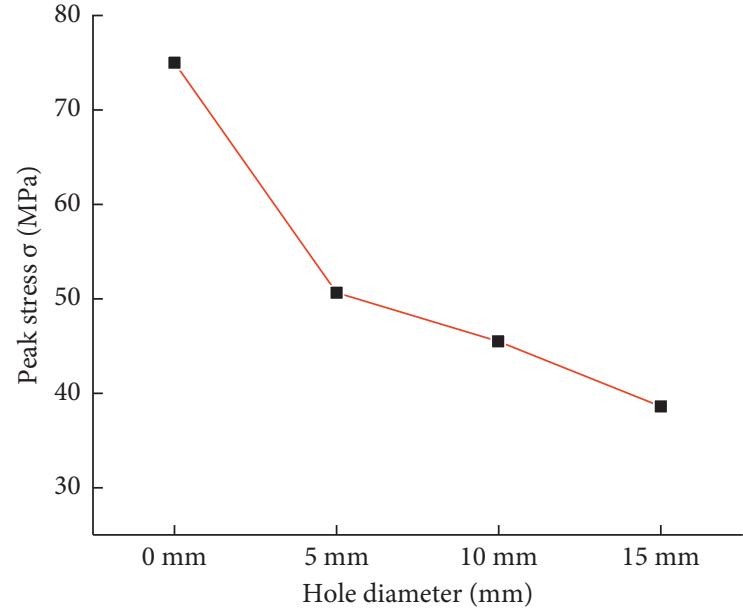

(a)

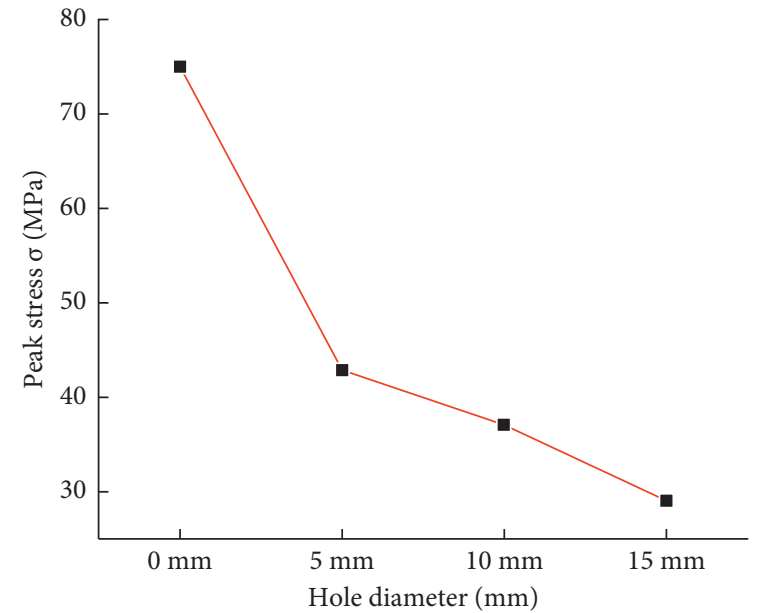

(b)

Figure 4: Peak stress on the rock with different diameters of the hole. (a) Peak stress on the rock with different diameters of the horizontal hole. (b) Peak stress on the rock with different diameters of the vertical hole.

the peak stress on the rock in the failure state is $42.7 \mathrm{MPa}$, reduced by $44.2 \%$ compared with the intact rock; if the hole diameter is $10 \mathrm{~mm}$, the average peak stress is $37 \mathrm{MPa}$, significantly reduced by $51.1 \%$; if the hole diameter is $15 \mathrm{~mm}$, the average peak stress is $28.8 \mathrm{MPa}$, reduced by $62.2 \%$. In contrast, the peak stress on the rock with the vertical hole is as presented in Figure 4(b), where the peak stresses on rocks with $\Phi 5 \mathrm{~mm}, \Phi 10 \mathrm{~mm}$, and $\Phi 15 \mathrm{~mm}$ holes are, respectively, $50.6 \mathrm{MPa}, 45.5 \mathrm{MPa}$, and $38.6 \mathrm{MPa}$, reduced by $33.1 \%$, $40 \%$, and $49 \%$, respectively. In comparison, the rock sample with the horizontal hole has a low level of stress drop.

3.2. The Impact of Different Hole Positions and Diameters on the Failure Pattern of the Rock Sample. As shown in Figure 5(a), the intact rock sample is being damaged, which is the typical characteristic of brittle failure of the intact rock sample and well corresponds to Figure 3, where the bearing capacity of the intact rock sample quickly becomes 0 when the stress-strain curves exceed the peak point. Figure 5(b) presents the failure characteristics of the rock sample with $\Phi 5 \mathrm{~mm}$ horizontal hole, where the number represents the order of crack expansion. Under the loading of axial stress, initial cracks $1 \mathrm{a}$ and $1 \mathrm{~b}$ appear in the central part of the hole for the first time. Crack $1 \mathrm{~b}$ expands upward along with the axial stress on the rock sample and produces tensile crack for the reason that stress concentration occurs above the hole under the action of uniaxial load on the rock sample with the hole. With the continuous loading, newborn wing-shape tensile crack 2 and distant crack 3 appear, where the distant crack is produced when the interior stress exceeds the extreme stress under the action of uniaxial load on the rock 


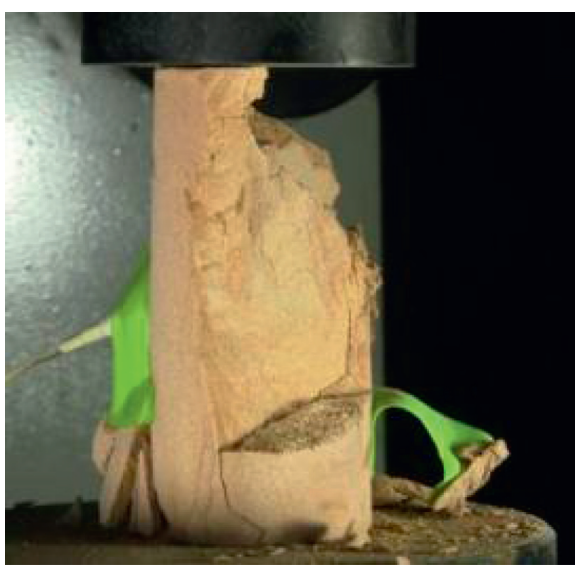

(a)

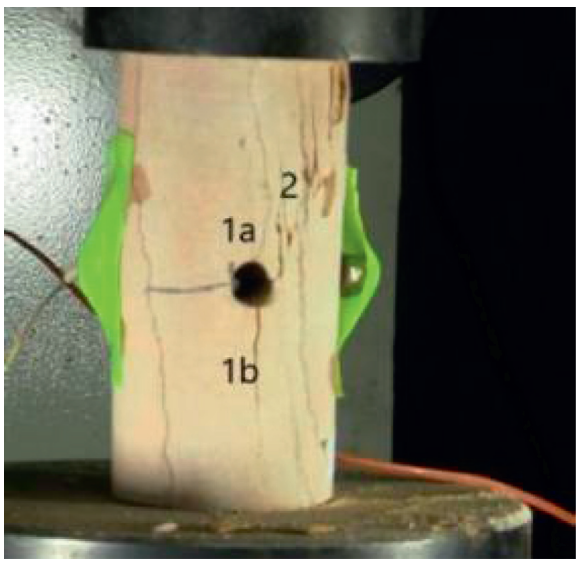

(c)

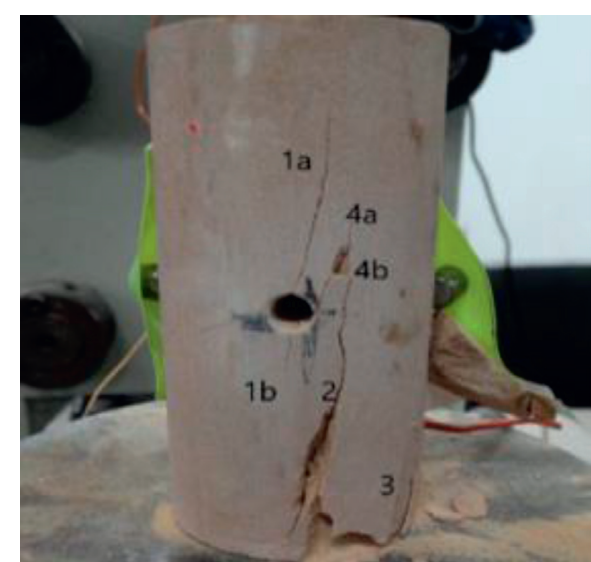

(b)

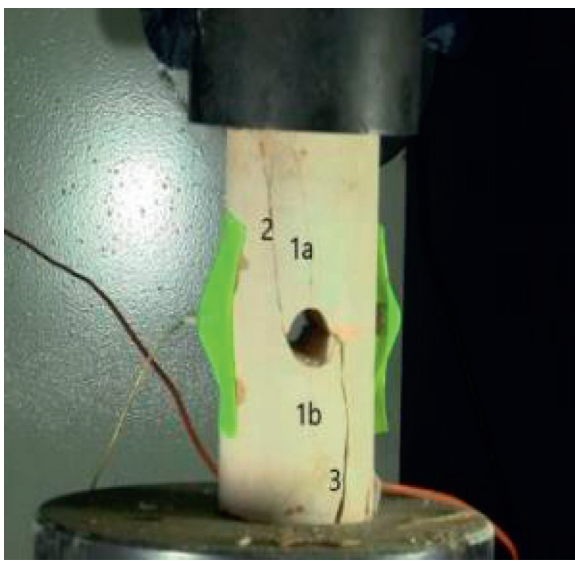

(d)

FIGURE 5: Failure patterns of the rock sample with different diameters of the horizontal hole. (a) Failure pattern of the intact rock sample. (b) Failure pattern of the rock sample with $\Phi 5 \mathrm{~mm}$ hole. (c) Failure pattern of the rock sample with $\Phi 10 \mathrm{~mm}$ hole. (d) Failure pattern of the rock sample with $\Phi 15 \mathrm{~mm}$ hole.

sample. Later with further loading, tensile crack 4a emerges at the right end of the hole and connects with crack 2 . The surface peeling failure at $4 \mathrm{~b}$ may be caused by the stress concentration in the loading process. Next, crack 2 quickly expands downward and finally penetrates through and connects with crack 3 , leading to the final failure of the rock sample.

Figure 5(c) shows the failure pattern of the rock with $\Phi 10 \mathrm{~mm}$ hole. As clearly demonstrated in the figure, the characteristic of the crack changes with the change in hole diameter. First, with the loading of axial stress, the crack change is similar to that when the hole diameter is $5 \mathrm{~mm}$, namely, vertical tensile cracks $1 \mathrm{a}$ and $1 \mathrm{~b}$ appear above and below the hole. However, with the continuous increase in axial stress, shear crack 2 comes out at the right end of the hole and extends to the right upper end of the rock. The right compression-shear crack may be caused by the pressure and stress concentration on the right and left of the hole under the action of uniaxial load on the rock with the hole. Followed by this, several secondary cracks appear around the right shear crack, accompanied by "kar kar" noise and falling debris from the rock sample, which well correspond to the two stress drops shown in the stress-strain curves of the rock with the hole. Eventually, the right shear crack expands to the right end of the rock, causing the final failure of the rock.

Figure 5(d) illustrates the failure characteristics of the rock sample with $\Phi 15 \mathrm{~mm}$ hole. At the beginning, crack is generated in the same way as the crack on rock samples with $\Phi 5 \mathrm{~mm}$ hole and $\Phi 10 \mathrm{~mm}$ hole, respectively, namely, tensile cracks $1 \mathrm{a}$ and $1 \mathrm{~b}$ appear in the middle part of the hole. Then, a large amount of broken rocks fall off from the above of the hole to the inside of the hole, which indicates that, with the increase in hole diameter, the action of the hole becomes more and more distinct. With the continuous loading of stress, shear crack 2 appears at the left end of the hole, and then the right lower end of the hole emits a noise of "kar," followed by a stress drop which can be clearly observed in the stress-strain curves. Next, shear crack 3 comes out at the right lower end of the hole and is in bilateral symmetry with shear crack 2 in the initial position. Later, shear crack 2 extends to the left upper end, and crack 3 extends to the right lower end, finally resulting in significant shear failure on the rock sample. For the rock sample with $\Phi 5 \mathrm{~mm}$ hole, tensile failure is dominant in the rock failure, while the failure of the rock sample with $\Phi 10 \mathrm{~mm}$ hole is dominated by right shear failure and that of the rock sample with $\Phi 15 \mathrm{~mm}$ hole is 
dominated by shear failure. As observed, for the rock sample with the horizontal hole, under the action of horizontal stress, the rock failure is gradually changed from tensile failure to shear failure with the increase in hole diameter.

In case of the vertical hole, the failure patterns of rock samples with different hole diameters are as shown in Figure 6 and quite different from those of the intact rock sample (Figure 6(a)). Figure 6(b) presents the crack failure characteristics of the rock sample with $\Phi 5 \mathrm{~mm}$ vertical hole. In the initial loading stage, the left bottom of the rock sample presents backward tensile crack 1 and then shows pulling crack 2 and shear crack 3 . With the continuous loading of stress, crack 3 coincides with crack 2, forming into a Y-shaped crack. Meanwhile, crack 2 extends to the top and bottom of the rock sample, small shear crack 4 occurs at the top, and the left side of crack 2 presents several pulling cracks connected to backward crack 1, resulting in the final failure pattern of the rock sample.

Figure 6(c) demonstrates the crack failure pattern of the rock sample with $\Phi 10 \mathrm{~mm}$ vertical hole which is somewhat similar to that of the rock sample with $\Phi 5 \mathrm{~mm}$ vertical hole. First, the rock sample presents pulling crack 1, and then obvious shear crack 2 appears. Followed by this, the two cracks connect with each other and form into a Y-shaped crack. At the same time, pulling crack 3 comes out. With the continuous enlarging of stress, the Y-shaped crack and pulling crack 3, respectively, extend toward the top and bottom of the rock, accompanied with significant peeling of the partial sample piece. The rock failure is mainly caused by the Y-shaped crack extending to the bottom of the rock, compared with that of the rock sample with $\Phi 5 \mathrm{~mm}$ vertical hole. Figure 6(d) illustrates the crack failure pattern of the rock sample with $\Phi 15 \mathrm{~mm}$ vertical hole which is different from that of the rock samples with $\Phi 5 \mathrm{~mm}$ and $\Phi 10 \mathrm{~mm}$ vertical holes. The initial crack is backward crack 1 that appeared at the right lower part of the rock sample followed by the peeling of a large piece of rock, which seriously affects the stability of the rock sample. Later, large tensile crack 2 appears, and crack 1 extends upward, accompanied with the derivation of several small cracks around it.

With the peeling of broken rock pieces, crack 1 extends to the extent paralleling with the initial end of tensile crack 2 . Accompanied with a drastic sound, shear crack 3 comes out and directly extends to the bottom of the rock sample, resulting in the $\mathrm{N}$-shaped final crack failure. In combination with the Y-shaped crack failures of rock samples with $\Phi 5 \mathrm{~mm}$ and $\Phi 10 \mathrm{~mm}$ vertical holes, it is revealed that the increase in hole diameter affects the expansion of the crack and the final pattern of failure. Meanwhile, the rock sample with different hole positions also shows completely different crack expansion and failure pattern. This implies that the expansion in the hole position also has a great impact on rock failure.

\section{Dissipative Energy Analysis}

4.1. Theories of Energy Conversion and Dissipation of the Rock in the Loading Process. In the loading process for the test, the energy continually input into the rock by press was converted into elastic energy and dissipated energy. In ideal conditions, according to the first law of thermodynamics, the total energy, elastic strain energy, and dissipated energy of a rock under uniaxial loading should comply with the following relationship:

$$
W=W_{s}-W_{d}
$$

In the equation, $W$ is the total energy input by the press, in $\mathrm{kJ} / \mathrm{m}^{3} ; W_{s}$ is the elastic strain energy accumulated inside the coal sample, in $\mathrm{kJ} / \mathrm{m}^{3} ; W_{d}$ is the energy dissipated in this loading process, in $\mathrm{kJ} / \mathrm{m}^{3}$.

The total energy can be calculated as per the area enclosed by the stress-strain curve, while the elastic strain energy can be calculated as per the unloading area enclosed by the stress-strain curve. The relationship between the two energies is illustrated in Figure 7.

This figure shows the stress-strain curve of the rock in the loading process. $W_{i}^{s}$ represents the elastic strain energy, which can be calculated by using the area enclosed by the curve; $W_{i}^{d}$ represents the energy dissipated in the loading process, which is irreversible and can be calculated by the difference between the total energy and elastic strain energy; $E_{i}$ is the elastic modulus. This research is mainly to study the conversion and dissipation of energy in the rock at the loading peak. If the loading condition is not available, $E_{i}$ cannot be calculated. In this case, $E_{i}$ can be replaced with the elastic modulus $E$ of the loading curve.

Based on the above discussion, the total energy $W$ and elastic strain energy $W_{s}$ of the rock under loading by uniaxial compression can be calculated as per the following equation:

$$
\begin{aligned}
W & =\int \sigma \mathrm{d} \varepsilon=\sum_{i=1}^{n-1} \int_{\varepsilon_{i}}^{\varepsilon_{i+1}} \sigma_{i} \mathrm{~d} \varepsilon \\
& =\sum_{i=1}^{n-1} \frac{\varepsilon_{i+1}-\varepsilon_{i}}{2}\left(\sigma_{i+1}+\sigma_{i}\right), \\
W_{s} & =\frac{1}{2} \sigma_{i}\left(\varepsilon_{i}-\varepsilon_{d}\right) \\
& =\frac{\sigma_{i}^{2}}{2 E d} \approx \frac{\sigma_{i}^{2}}{2 E} .
\end{aligned}
$$

In the equation, $\varepsilon_{\mathrm{i}}$ is the strain of the coal sample when the stress is at $\sigma_{i} ; E_{d}$ is the elastic modulus of the unloading stress-strain curve; $E$ is the elastic modulus of the loading curve; and $\varepsilon_{d}$ is the strain unrecoverable after being unloaded from $\sigma_{i}$ to zero. Then, the dissipated energy $W_{d}$ in the rock loading process is

$$
W_{d}=W-W_{s}
$$

4.2. The Impact of Different Hole Positions on the Energy Conversion of the Rock in the Loading Process. According to Figure 8, a comparison was made on the conversion of elastic energy and dissipated energy in rocks with different hole positions and the elastic energy conversion ratios of 


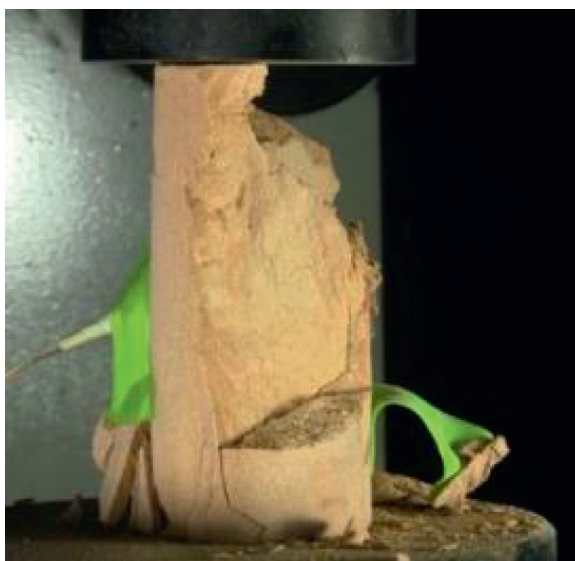

(a)

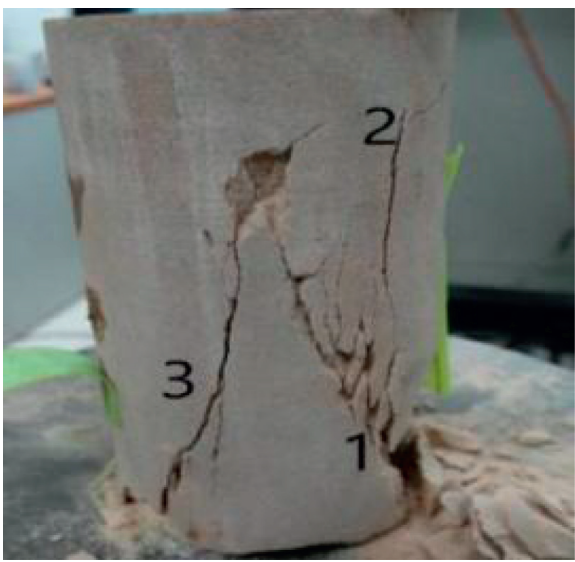

(c)

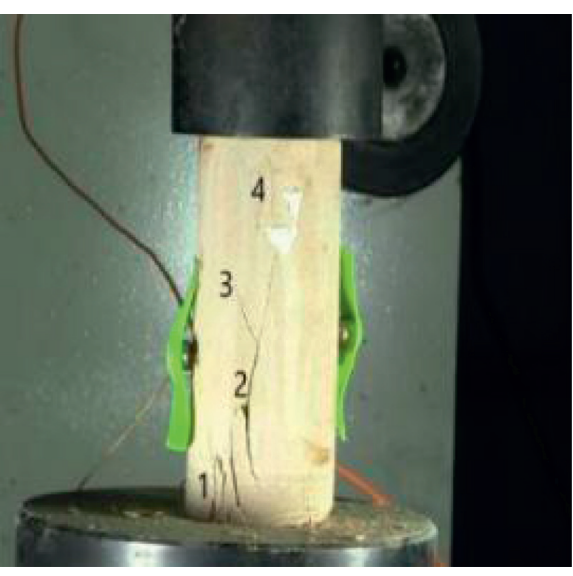

(b)

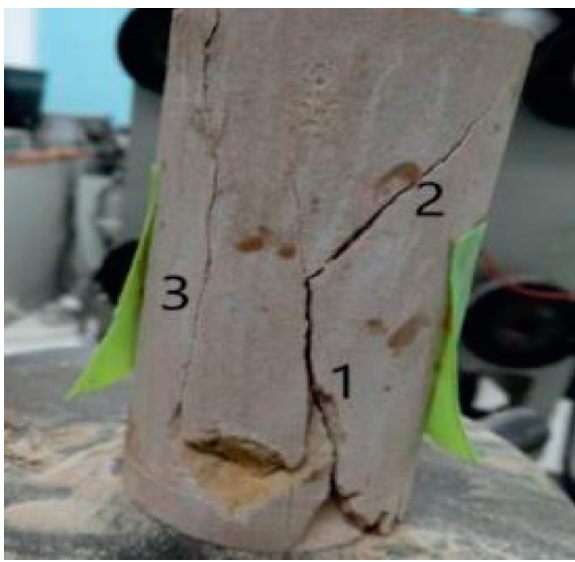

(d)

FIGURE 6: Failure patterns of the rock sample with different diameters of the vertical hole. (a) Failure pattern of the intact rock sample. (b) Failure pattern of the rock sample with $\Phi 5 \mathrm{~mm}$ hole. (c) Failure pattern of the rock sample with $\Phi 10 \mathrm{~mm}$ hole. (d) Failure pattern of the rock sample with $\Phi 15 \mathrm{~mm}$ hole.

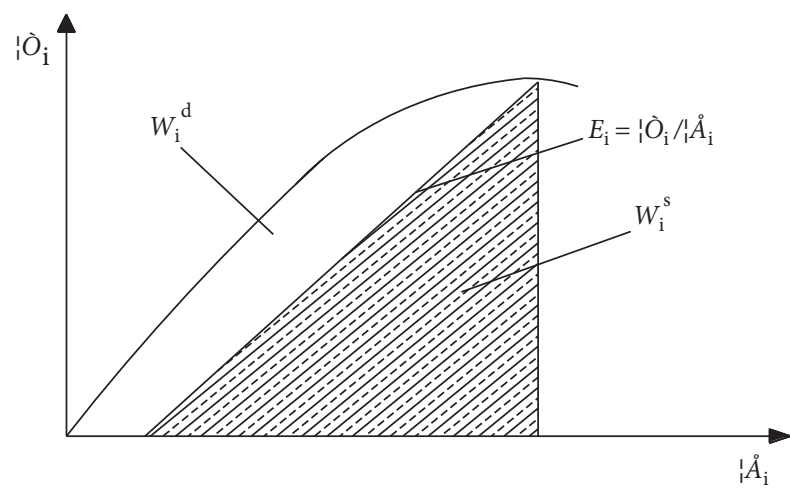

FIGURE 7: The relationship between elastic strain energy and dissipated energy in the rock unit.

rock samples E05 and B05. The results reveal that $79.68 \%$ of the total energy input in rock B05 with the horizontal hole is stored in the rock in the form of elastic energy, while in rock E05 with the vertical hole, $90.19 \%$ of the total energy is converted into elastic energy and stored in the rock. The greater the strength, the greater the deformation and the more energy accumulation, which are roughly in

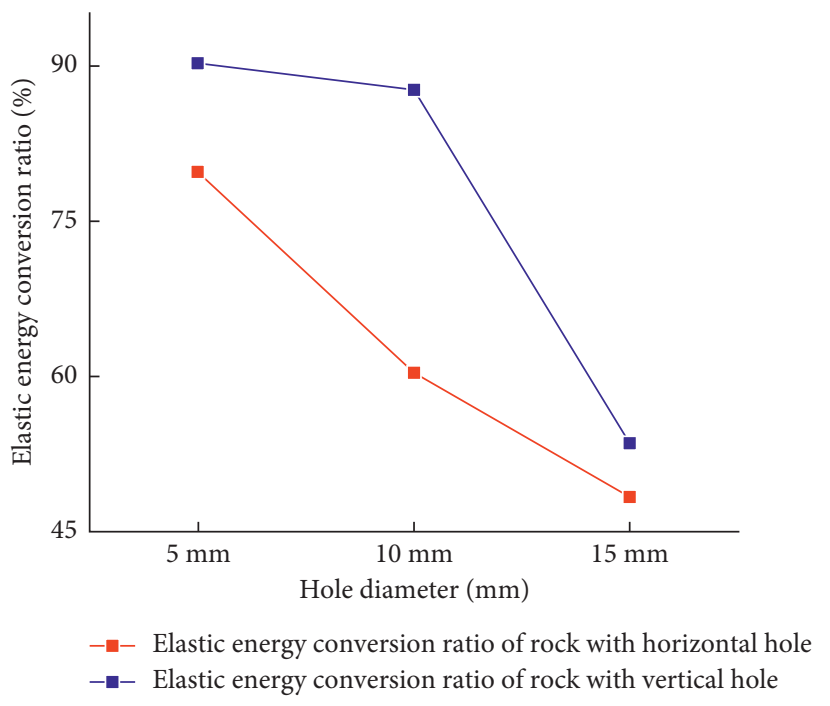

FIGURE 8: Elastic energy conversion ratio of the rock with different hole positions.

direct proportion. Hence, the failure of the rock with the vertical hole is severer than that of the rock with the horizontal hole of the same diameter, which can be 
explained from the perspective of energy conversion because the accumulation degree of elastic energy is directly proportional to the intensity of energy released and the failure intensity. The elastic energy conversion ratio of rock $\mathrm{C} 10$ with the horizontal hole is smaller than that of rock F10 with the vertical hole. This indicates that the horizontal hole has better pressure relief effect than the vertical hole and explains from the energy conversion point of view that the rock with the horizontal hole often subjects to greater impact from the existence of the hole than the rock with the vertical hole of the same diameter if the mechanical properties inside the rock are affected by the hole. Furthermore, the elastic energy conversion ratio of rock D15 with the horizontal hole is slightly higher than that of rock G15 with the vertical hole, which implies that, for the rock with $\Phi 15 \mathrm{~mm}$ hole, there is no too large difference between the impacts of different hole positions on the rock failure. Therefore, from the perspective of energy conversion, it is explained that when the hole diameter is $15 \mathrm{~mm}$, there is no large difference between the impacts of horizontal and vertical holes on the brittleness and elastic modulus of the rock.

\section{Experimental Study Based on Acoustic Emission}

5.1. The Impact of Different Hole Diameters on the Acoustic Emission Characteristics of the Rock Sample in the Process of Loading. The acoustic emission characteristics of rock samples with the horizontal hole of different diameters are as shown in Figure 9. Figure 9(a) shows the acoustic emission frequency of an intact rock sample, which has larger acoustic emission change characteristics than the rock sample with the hole. This is mainly because the crack and microhole in the intact crack expand fully in the stress loading process, resulting in large accumulation of energy in the rock. When the internal crack is not fully developed, macrocrack expands toward the edge of the rock along the cracking direction of the hole so that failure has appeared before the internal crack is fully developed.

And this phenomenon is more and more obvious with the increase in the hole diameter. At first, as shown in Figure 9(b), the acoustic emission frequency is high when the hole is of $5 \mathrm{~mm}$ in diameter and becomes low when the hole diameter is $10 \mathrm{~mm}$ (Figure 9(c)). This evolution law is further verified when the hole is of $15 \mathrm{~mm}$ in diameter as displayed in Figure 9(d). This also verifies the brittle failure of the intact rock so that the accompanied acoustic emission frequency is high. It is the existence of the hole that causes pulling shear failure.

As a result, the hole diameter is directly proportional to the pressure relief effect and inversely proportional to the acoustic emission characteristics.

The acoustic emission characteristics of rock samples with the vertical hole of different diameters are as shown in Figure 10.

Over a comparison with the acoustic emission frequency of the intact rock sample (Figure 10(a)), it is acknowledged that the vertical hole has a larger impact on the acoustic emission characteristics of the rock, and the acoustic emission characteristics vary greatly with the increase in hole diameter.

At the beginning of loading, the acoustic emission frequency is inversely proportional to the hole diameter, mainly for the reason that the internal crack of the rock is fully expanded with the increase in hole diameter. With the continuous loading of axial stress, different precursory information of acoustic emission, respectively, appeared on rocks with $\Phi 5 \mathrm{~mm}$ hole (Figure 10(b)), $\Phi 10 \mathrm{~mm}$ hole (Figure 10(c)), and $\Phi 15 \mathrm{~mm}$ hole (Figure $10(\mathrm{~d})$ ) at $210 \mathrm{~s}, 225 \mathrm{~s}$, and $185 \mathrm{~s}$. The intact rock sample has no obvious precursory information except for the sudden increase in acoustic emission caused by stress drop. Hence, in this phenomenon, it is the existence of the vertical hole that caused the appearance of precursory information of failure on the rock with the vertical hole. When the stress loaded on the intact rock sample and rock samples with $\Phi 5 \mathrm{~mm}$ hole, $\Phi 10 \mathrm{~mm}$ hole, and $\Phi 15 \mathrm{~mm}$ hole, respectively, reaches $40 \%, 25 \%, 22 \%$, and $12.5 \%$ of the peak stress, the rock samples enter the plastic stage. In this stage, their acoustic emission signals are greatly different, where the intact rock sample has the strongest acoustic emission signal, followed by rock samples with $\Phi 5 \mathrm{~mm}$ hole and $\Phi 10 \mathrm{~mm}$ hole, and this signal of the rock sample with $\Phi 15 \mathrm{~mm}$ hole is the weakest. However, when entering the subinstability loading stage, this signal of the rock sample with $\Phi 15 \mathrm{~mm}$ hole is the strongest, followed by that of rock samples with $\Phi 10 \mathrm{~mm}$ hole, $\Phi 5 \mathrm{~mm}$ hole, and $\Phi 0 \mathrm{~mm}$ hole in turn. The main reason is that the larger the hole diameter is, the more unavailable it is for the internal crack to fully expand so that the rock in the hole still has a certain bearing capacity after failure after loading. Thereby, the bearing capacity of the rock after the loading peak is directly proportional to the hole diameter. It is for this reason that, in the subinstability loading stage, the acoustic emission signal is strong and severe.

Nevertheless, the acoustic emission evolution characteristics of the rock samples with different diameters of holes are similar. Such evolution characteristics are divided into 4 stages and analyzed in detail as follows:

(1) Compaction stage: in the initial compaction stage, the acoustic emission signals of the rock sample are scattered for the reason that the internal of the rock sample is in the compaction period of the original crack. In this stage, the acoustic emission signal is relatively weak.

(2) Elastic stage: with the continuous increase in axial stress, the original crack enters the elastic stage. In this stage, the stress is in direct proportion to the strain. The acoustic emission signal appeared is weak as the applied load is not enough to have the internal crack of the rock sample expanded greatly. However, compared with the previous stage, the acoustic emission signal in this stage is apparently strong and becomes significantly strong in the later period of the elastic stage. 


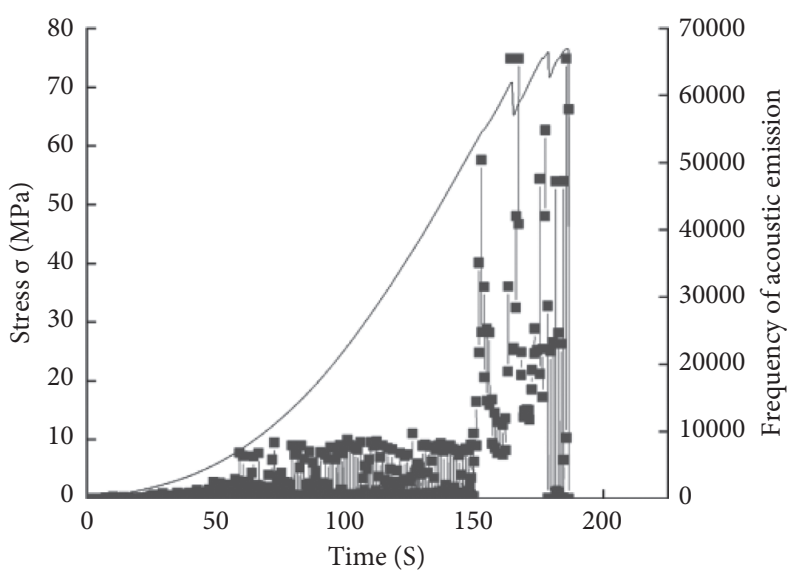

(a)

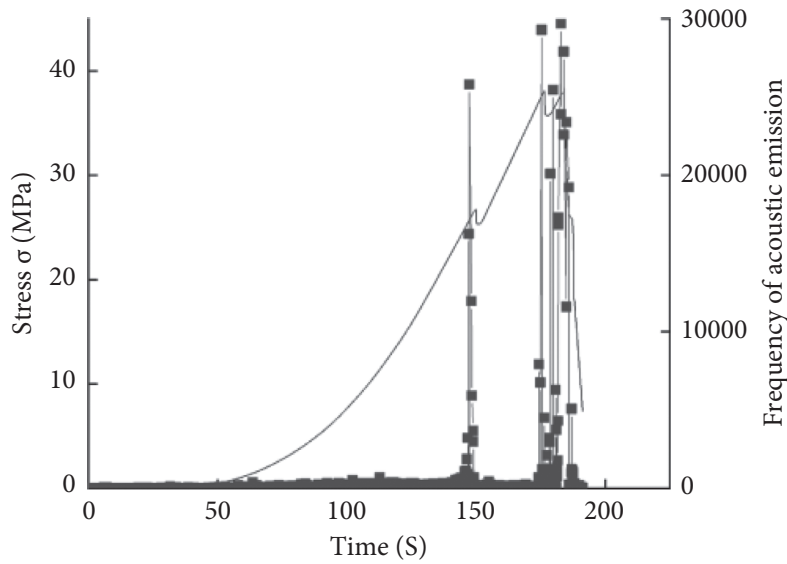

(c)

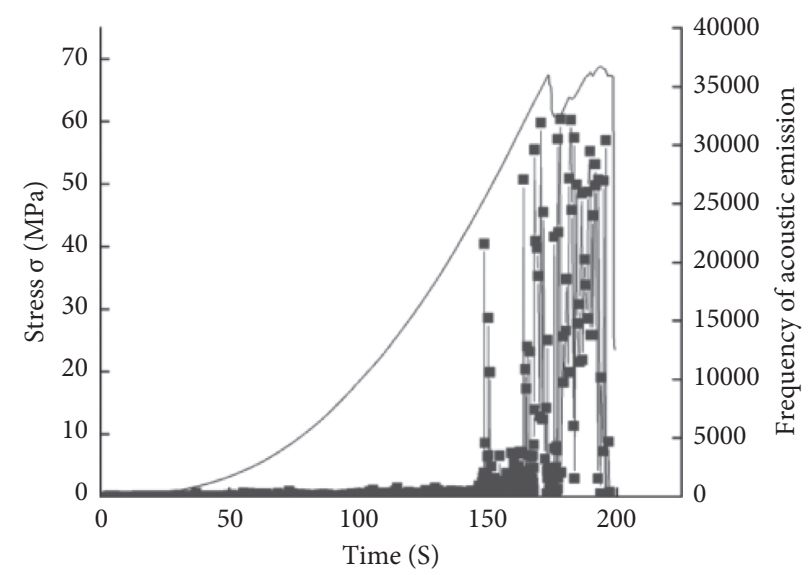

(b)

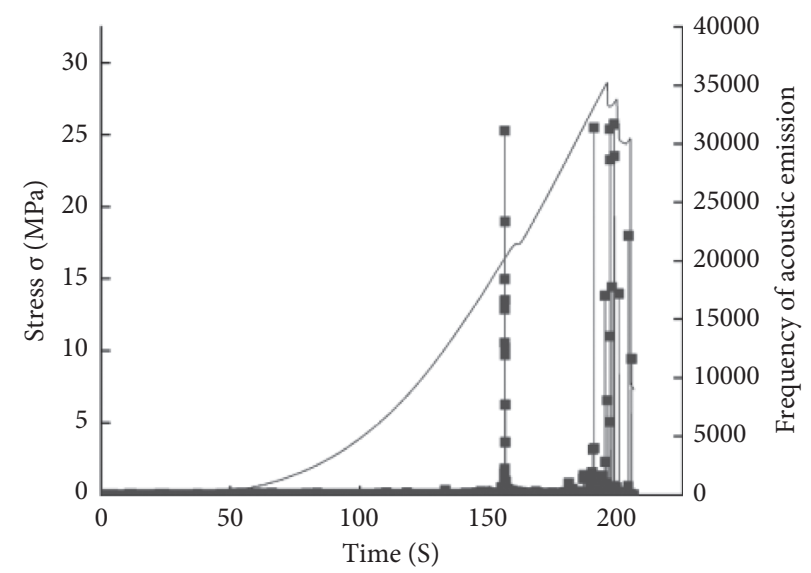

(d)

FIGURE 9: Stress-time-acoustic emission information of the rock sample with the horizontal hole of different diameters. (a) Stress- $N$-time of rock A00. (b) Stress- $N$-time of rock B05. (c) Stress- $N$-time of rock C10. (d) Stress- $N$-time of rock D10.

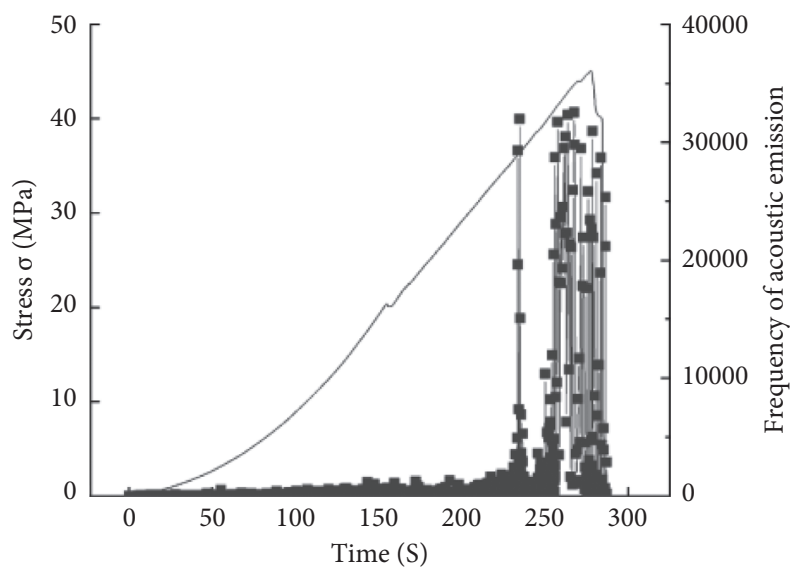

(a)

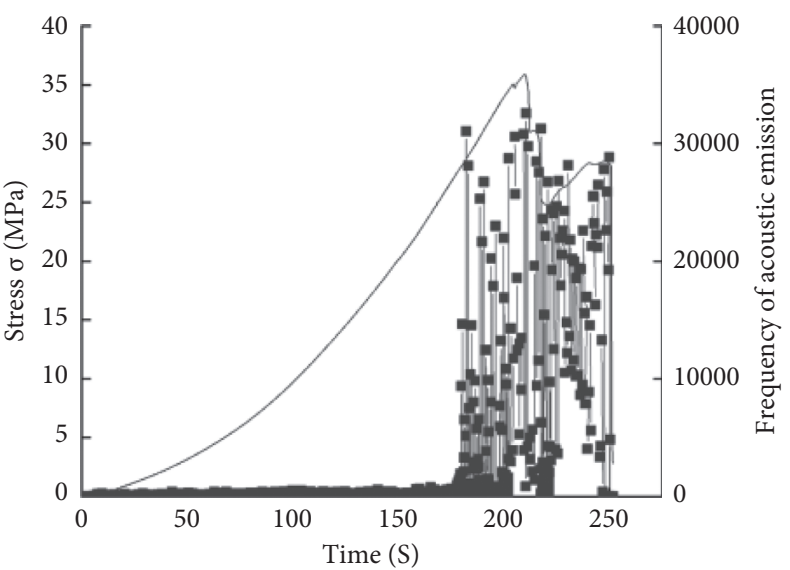

(b)

Figure 10: Continued. 


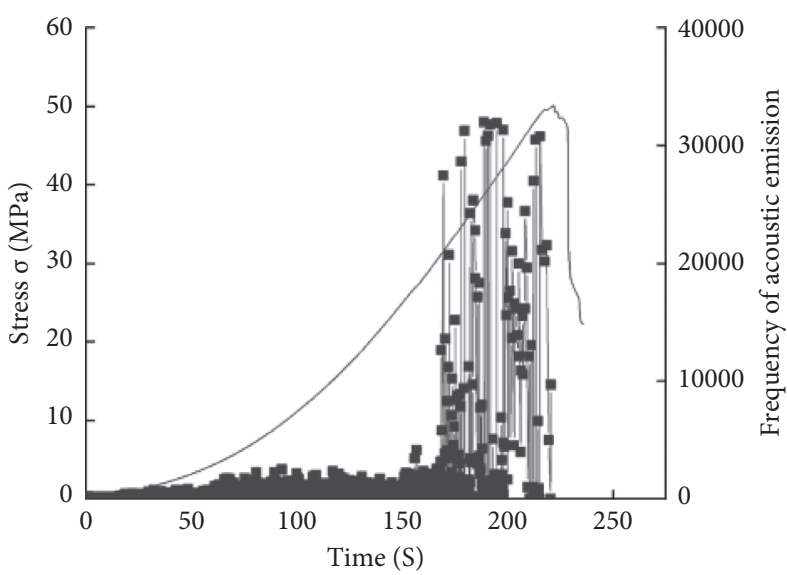

(c)

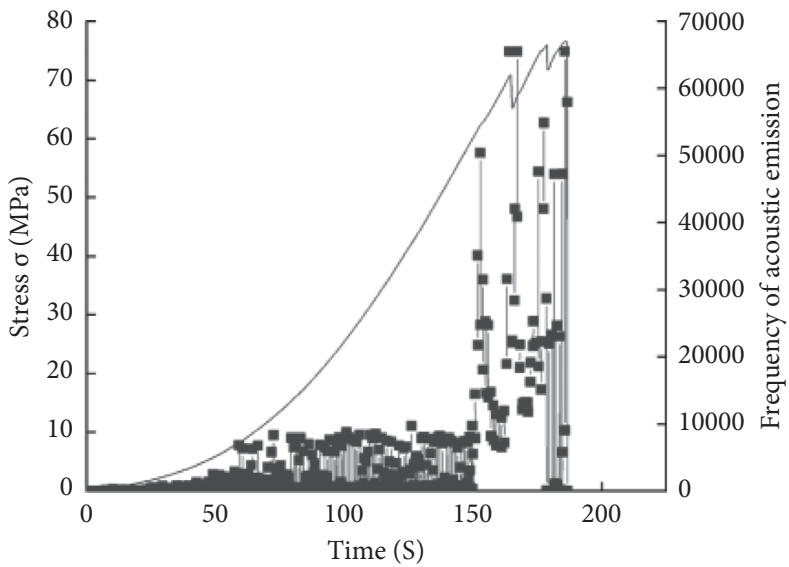

(d)

Figure 10: Stress-time-acoustic emission information of the rock sample with the vertical hole of different diameters. (a) Stress- $N$-time of rock A00. (b) Stress- $N$-time of rock E05. (c) Stress- $N$-time of rock F10. (d) Stress- $N$-time of rock G15.

(3) Plastic stage: after the original crack is compacted again, new cracks appear in the rock sample under the loading action so that the cracks expand, extrude, and rub with each other and slip, accompanied with the appearance of a large amount of macrocracks, resulting in a large increase in the acoustic emission frequency and energy.

5.2. Analysis of Acoustic Emission Characteristics of the Rock Sample with Different Hole Positions. According to Figure 11, a detailed analysis was made on the impact of different hole positions on the acoustic emission characteristics of the rock sample. As discovered by comparing the total acoustic emission signals of rock samples with different hole positions, the total acoustic emission signal of the rock sample with the vertical hole is stronger than that of the rock sample with the horizontal hole. This may be mainly caused by the difference in the force direction on the hole so that the internal crack of the rock sample with the vertical hole expands better than that of the rock sample with the horizontal hole. The rock sample with the horizontal hole and that with the vertical hole both undergo four acoustic emission evolution stages but have greatly different acoustic emission characteristics in the four stages. In the initial loading stage, the acoustic emission signal of the rock with the vertical hole is apparently slightly stronger than that of the rock with the horizontal hole. This indicates that, in this stage, the internal crack of the rock with the vertical hole is fully compacted, causing a stronger acoustic emission signal than that of the rock with the horizontal hole, since different positions of the hole are subject to different forces. In the early elastic stage, the position of the hole has little effect on the rock pattern on the acoustic emission signal of the rock sample.

However, in the later elastic stage, the rock sample with $\Phi 10 \mathrm{~mm}$ horizontal hole (Figure 11(c)) and that with $\Phi 15 \mathrm{~mm}$ horizontal hole (Figure 11(e)) both undergo uprush of the acoustic emission signal. Meanwhile, the rock sample with $\Phi 10 \mathrm{~mm}$ vertical hole (Figure $11(\mathrm{~d})$ ) and that with $\Phi 15 \mathrm{~mm}$ vertical hole (Figure 11(f)) also undergo such uprush, but for different reason. The uprush of the rock sample with the horizontal hole is mainly caused by stress drop, indicating the instable state of the rock sample in this stage, while that of the rock sample with the vertical hole is mainly caused by the expansion of the internal crack. In comparison, the rock sample with the vertical hole has begun the continuous emission of acoustic signals in the later elastic stage, while the acoustic emission signal of the rock sample with the horizontal hole undergoes a small quiet period after stress drop in the later elastic stage, followed by a large amount of acoustic emission signals in the later plastic stage. This further verifies that the uprush of such signal in the later elastic stage is caused by stress drop, and in the elastic stage, the internal crack of the rock sample with the vertical hole expands better than that of the rock sample with the horizontal hole. According to the acoustic emission frequencies of rock samples with different hole positions as generally shown in Figure 11, the density of the rock with the vertical hole is higher than that of the rock with the horizontal hole and maintains this law in the residual strength stage. This demonstrates that different positions of holes are subject to different force directions and thus have a large impact on the acoustic emission characteristics of the rock sample.

\section{Characteristic Analysis of the Damage Model}

6.1. Establishment and Derivation of the Damage Model. As proved by a large number of experiments, acoustic emission ringing frequency can well reflect the variation in the property of a material and is directly proportional to the expansion and evolution characteristics of the crack inside the material. Therefore, acoustic emission ringing frequency is selected as a characteristic parameter for description in order to discuss the damage evolution law of sandstone. The damage variable is defined by the former Soviet researcher L. M. Kachanov as 


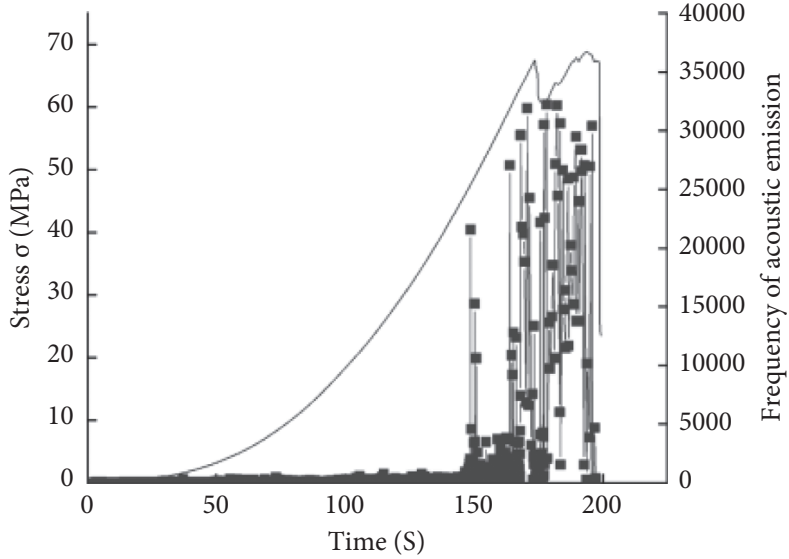

(a)

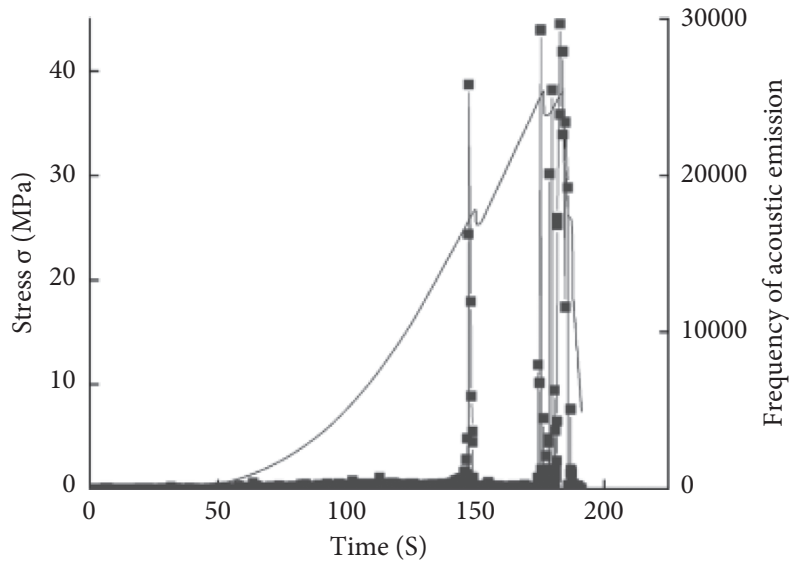

(c)

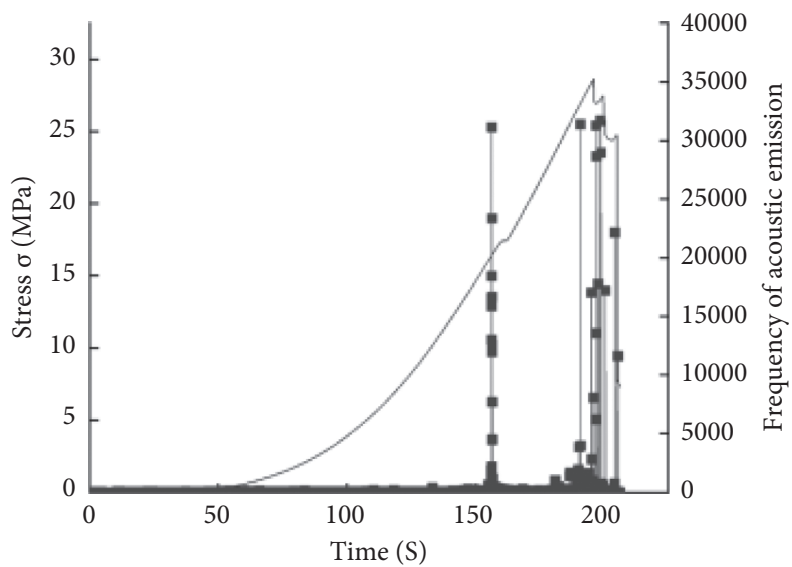

(e)

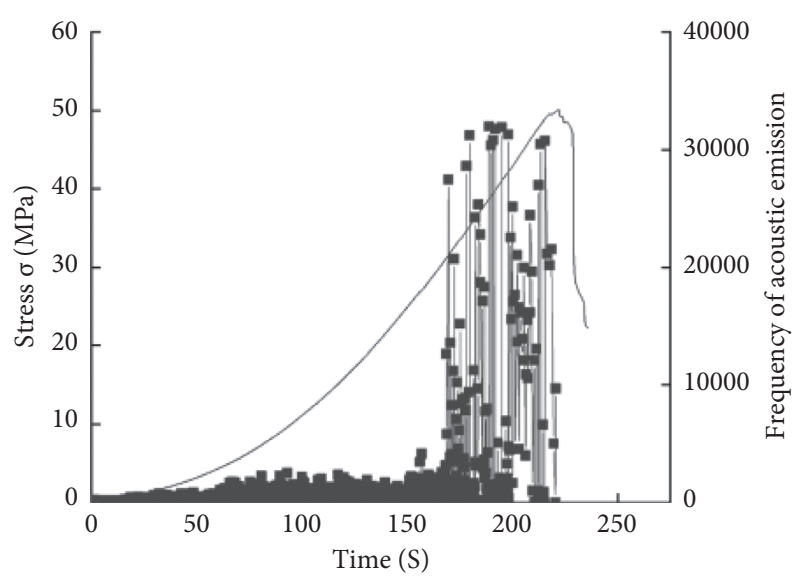

(b)

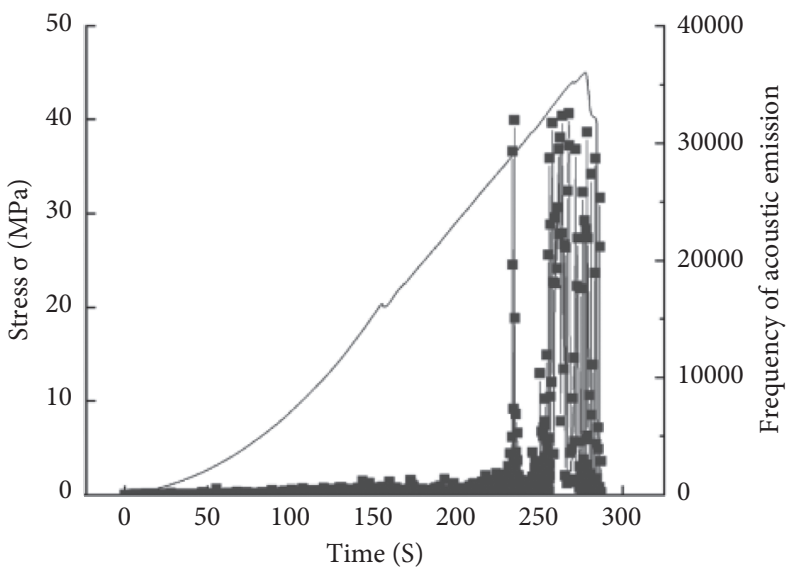

(d)

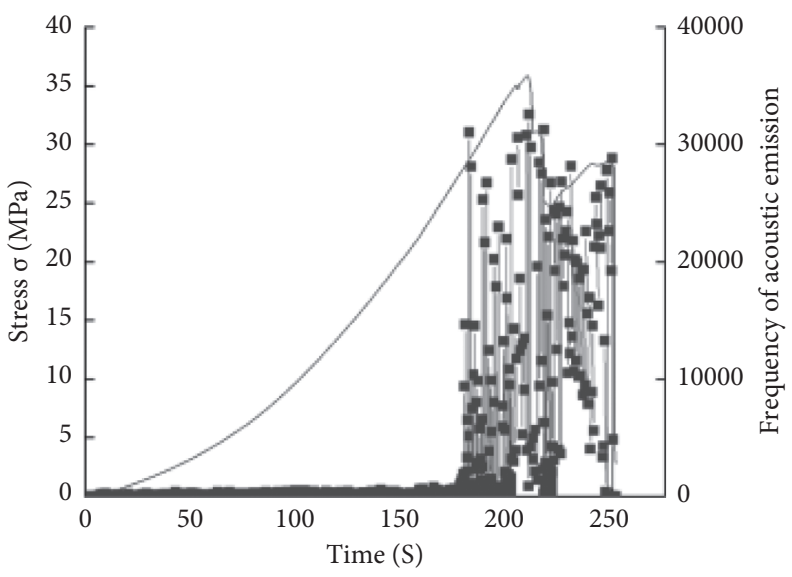

(f)

FIGURE 11: Stress-time-acoustic emission information of the rock sample with different hole positions. (a) Stress- $N$-time of rock B05. (b) Stress- $N$-time of rock E05. (c) Stress- $N$-time of rock C10. (d) Stress- $N$-time of rock F10. (e) Stress- $N$-time of rock D15. (f) Stress- $N$-time of rock G15. 


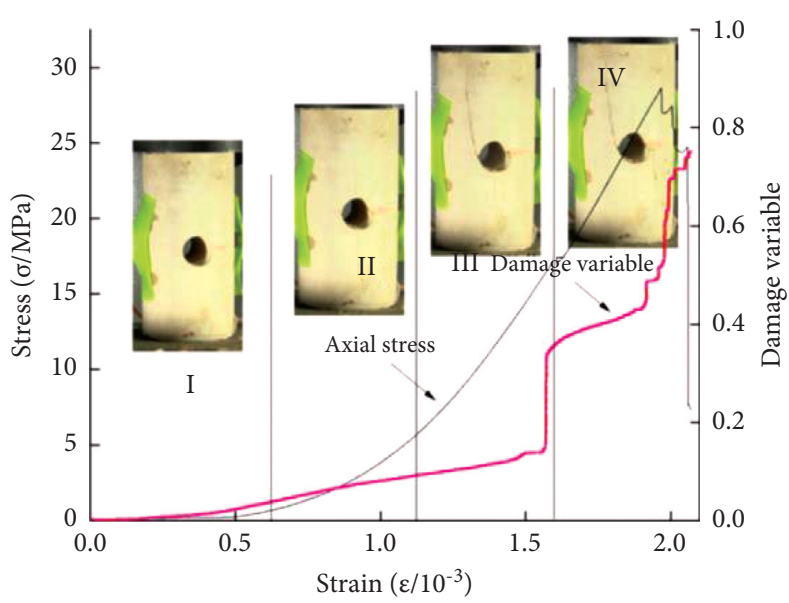

(a)

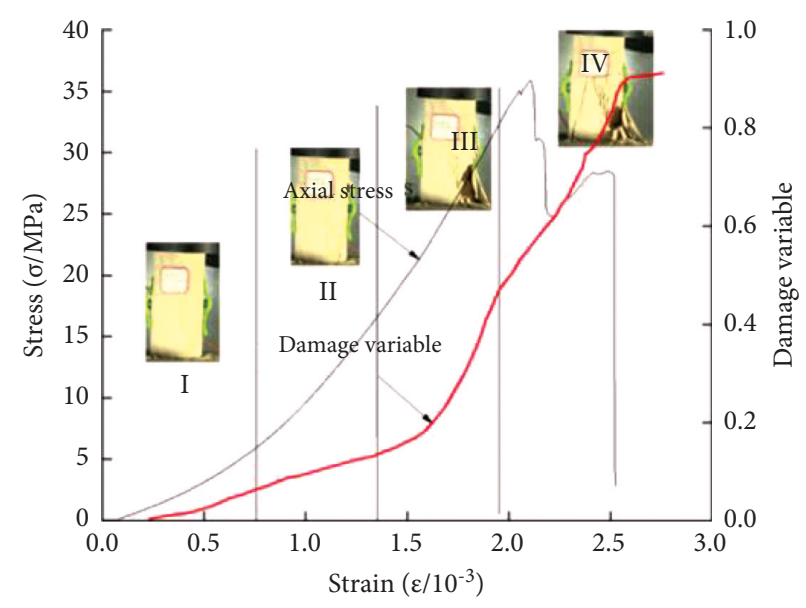

(b)

Figure 12: Damage-stress-strain relationship of rock samples with $\Phi 15 \mathrm{~mm}$ hole at different positions. (a) Damage-stress-strain relationship of rock D15. (b) Damage-stress-strain relationship of rock G15.

$$
D=\frac{A_{d}}{A}
$$

In the equation, $A_{d}$ is the damaged cross-sectional area of the rock showing obvious crack under pressure; and $A$ is the undamaged cross-sectional area of the rock under stress loading. Assuming that the cumulative ringing frequency in the evolution process of the undamaged area $A$ from a complete state to a complete damage state is recorded as $W_{0}$, the acoustic emission ringing frequency of infinitesimal damage of unit area is recorded as $W_{C}$ :

$$
W_{C}=\frac{W_{O}}{A} .
$$

Therefore, when the damaged cross-sectional area reaches $A_{d}$, the cumulative acoustic emission frequency $W_{d}$ is calculated as follows:

$$
\begin{aligned}
W_{d} & =W_{C} A_{d}=\frac{W_{o}}{A} A_{d}, \\
D & =\frac{W_{d}}{W_{O}} .
\end{aligned}
$$

The initial damage can be defined by initial porosity, but in the author's opinion, it is more suitable to define the critical point in the compaction stage as initial damage. Therefore, the initial damage value is defined by proposing the critical stress and stress intensity in the initial compaction stage:

$$
D_{O}=\frac{\sigma_{m}}{\sigma_{c}}
$$

In the equation, $D_{O}$ is the initial damage value; $\sigma_{m}$ is the critical stress in the initial compaction stage; $\sigma_{c}$ is the peak strength of stress on the rock, which can be determined by the stress-strain curve.

Due to different failure conditions of different rocks or the insufficient hardness of the testing machine, it is a common thing that the testing machine has stopped running before the rock sample reaches a complete failure state (namely, the damage does not reach 1). Hence, the critical value of damage is defined as follows:

$$
D_{c}=1-\frac{\sigma d}{\sigma c}
$$

In the equation, $D_{c}$ is the critical damage value; $\sigma_{d}$ is the residual strength.

According to the research results of Liu Baoxian et al., the initial damage and critical damage are unified in the normalization method and then corrected, obtaining the damage evolution equation including initial damage:

$$
D=D_{d}+\left(D_{C}-D_{O}\right) \frac{W_{d}}{W_{O}} .
$$

Thereby, the damage model based on acoustic emission characteristics of the rock under uniaxial compression is

$$
\begin{aligned}
\sigma & =(1-D) E \mathcal{\varepsilon} \\
& =\left[1-D_{0}-\left(D_{C}-D_{0}\right) \frac{W_{d}}{W_{O}}\right] E \varepsilon .
\end{aligned}
$$

Considering the length limit of the paper, only rock samples D15 and G15 are used for an analysis here. Figure 12 simulates the damage evolution process by loading. As the trends of damage relationship curves of the rock samples with different hole positions and diameters are almost the same, the damage evolution process of the rock sample with holes can be roughly divided into 4 stages (Figure 12), which well correspond to the four stages of the acoustic emission evolution characteristics of the rock sample with holes.

\subsection{Damage Mechanics Law of the Rock with Holes}

(1) Initial damage stage: the damage value at this stage is very low. Because initial compaction is in this stage, the original cracks do not expand. With the 
continuous increase of axial stress, only new tiny cracks appear and expand in the rock so that there are few acoustic emission events. And no obvious crack can be seen from the corresponding rock sample.

(2) Damage stabilization and increase stage: for rock samples with the horizontal hole, there are obvious cracks near the hole, while for rock samples with the vertical hole, the cracks appear at the lower right of the rock, and the microdamage tends to concentrate locally, gradually concentrate at the failure part of the rock, and evolve into macrocracks.

(3) Due to the mutual friction and collision of cracks in the rock sample, the parameters of acoustic emission in this stage undergo abnormal increase. At this time, the rock sample is extremely unstable and undergoes significant macrofailure and obviously fast crack expansion regardless of the hole position.

\section{Conclusion}

(1) As revealed by comparing the stress-strain curves of rock samples with different hole positions, the stages on the stress-strain curve that the rock with the vertical hole undergoes are all longer than those underwent by the rock with the horizontal hole, and the brittleness strength and the like mechanical properties of the rock with the vertical hole are higher than those of the rock with the horizontal hole. This indicates that the rock sample with the vertical hole has higher bearing capacity and stability than the rock sample with the horizontal hole of the same diameter.

(2) As for the failure characteristics of the rock sample with the horizontal hole, symmetric tensile cracks firstly appear in the upper and lower part of the hole, form into initial tensile failure, and finally turn into shear failure. With respect to the failure characteristics of the rock sample with the vertical hole, the final $\mathrm{N}$-shaped failure is formed from the initial Y-shaped failure with the increase in hole diameter. Compared with the failure pattern of the intact rock sample, the final failure pattern and crack expansion direction of the rock sample with holes can be changed with different hole positions and diameters.

(3) It is the existence of holes that changes the energy conversion in the rock. The hole diameter is inversely proportional to the elastic energy stored in the rock and directly proportional to the dissipated energy in the rock. The results of analysis on the energy conversion of the rock with different hole positions demonstrate that the elastic energy conversion ratio of the rock with the vertical hole is higher than that of the rock with the horizontal hole. Furthermore, an explanation was made on the difference between the failure processes of the two types of rocks from the perspective of energy conversion.

\section{Data Availability}

All data, models, or codes generated or used during the study are available in a repository or online in accordance with funder data retention policies.

\section{Conflicts of Interest}

The authors declare no conflicts of interest.

\section{Authors' Contributions}

Xiao Fukun designed research and completed most of the research work, followed by Li Renhe. Xing Le analyzed the data. All authors reviewed the manuscript.

\section{Acknowledgments}

This research was supported by the National Natural Science Foundation of China (51774121 and 52074110), Innovative Scientific Research Project for Postgraduates of Heilongjiang University of Science and Technology (YJSCX2020103HKD), and Joint Guidance Project of the Natural Science Foundation of Heilongjiang Province (LH2019E087 and LH2019E119).

\section{References}

[1] S.-q. Yang, H.-w. Jing, and T. Xu, "Mechanical behavior and failure analysis of brittle sandstone specimens containing combined flaws under uniaxial compression," Journal of Central South University, vol. 21, no. 5, pp. 2059-2073, 2014.

[2] Metallurgical Industry Press, Rock Failure Principle and Application, Metallurgical Industry Press, Beijing, China, 1994, in Chinese.

[3] E. Z. Lajtai and V. N. Lajtai, "The collapse of cavities," International Journal of Rock Mechanics and Mining Science \& Geomechanics Abstracts, vol. 12, no. 4, pp. 81-86, 1975.

[4] E. Z. Lajtai, "Shear strength of weakness planes in rock," International Journal of Rock Mechanics and Mining Science \& Geomechanics Abstracts, vol. 6, no. 5, pp. 499-515, 1969.

[5] S. Yang, C. Lv, and T. Qu, "Investigations of crack expansion in marble having a single pre-existing hole: experiment and simulations," Journal of China University of Mining \& Technology, vol. 38, no. 6, 2009, in Chinese.

[6] L. Cheng, S. Yang, and X. Liu, "Experimental and numerial investigation on crack expansion of sandstone containing flaws," Journal of Mining \& Safety Engineering, vol. 29, no. 5, pp. 719-724, 2012, in Chinese.

[7] S. Yang, X. Liu, and Y. Li, "Experimental analysis of mechanical behavior of sandstone containing hole and fissure under uniaxial compression," Chinese Journal of Rock Mechanics and Engineering, vol. 31, no. 2, pp. 3539-3546, 2012, in Chinese.

[8] D. Li, T. Cheng, T. Zhou et al., "Experimental study of the dynamic strength and fracturing characteristics of marble specimens with a single hole under impact loading," Chinese Journal of Rock Mechanics and Engineering, vol. 34, no. 2, pp. 249-260, 2015, in Chinese.

[9] R. Peng, H. Xie, J. Yang et al., "Effect of elastic accumulation energy of testing machine on the mechanical measurement of rocks," Mechanics in Engineering, vol. 27, no. 3, pp. 51-55, 2005, in Chinese. 
[10] C. Tang and $\mathrm{X} . \mathrm{Xu}$, "Evolution and propagation of material defects and Kaiser effect function," Journal of Seismological Research, vol. 13, no. 2, pp. 203-313, 1990.

[11] B. Liu, J. Huang, Z. Wang et al., "Study on damage evolution and acoustic emission character of coal-rock under uniaxial compression," Chinese Journal of Rock Mechanics and Engineering, vol. 28, no. S1, pp. 3234-3238, 2009, in Chinese.

[12] Y. Li, L. Chen, and Y. Wang, "Experimental research on precracked marble under compression," International Journal of Solids and Structures, vol. 42, no. 9, pp. 2505-2516, 2005.

[13] X.-d. Zhao, H.-x. Zhang, and W.-c. Zhu, "Fracture evolution around pre-existing cylindrical cavities in brittle rocks under uniaxial compression," Transactions of Nonferrous Metals Society of China, vol. 24, no. 3, pp. 806-815, 2014.

[14] S.-Q. Yang and H.-W. Jing, "Strength failure and crack coalescence behavior of brittle sandstone samples containing a single fissure under uniaxial compression," International Journal of Fracture, vol. 168, no. 2, pp. 227-250, 2011.

[15] H. Yankui and X. Nie, "Analysis of mechanical and acoustic emission characteristics of hole-fracture defective rocks," Geological Survey of China, vol. 6, no. 3, pp. 63-67, 2019, in Chinese.

[16] G.-1. Feng, B.-r. Chen, Q. Jiang, Y.-x. Xiao, W.-j. Niu, and P.-x. Li, "Excavation-induced microseismicity and rockburst occurrence: s," vol. 28, no. 2, pp. 582-594, Journal of Central South University, 2021.

[17] G.-L. Feng, X.-T. Feng, B.-r. Chen, Y.-X. Xiao, and Y. Yu, “A microseismic method for dynamic warning of rockburst development processes in tunnels," Rock Mechanics and Rock Engineering, vol. 48, no. 5, pp. 2061-2076, 2015. 